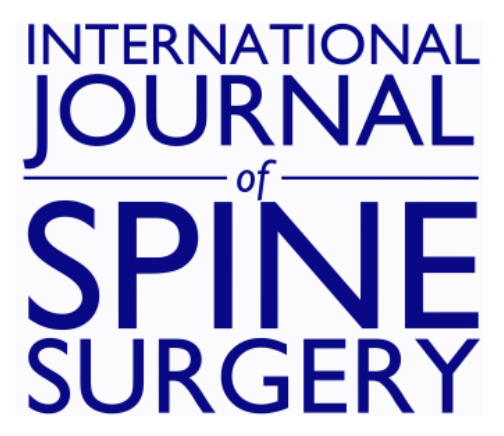

\title{
Multilevel Minimally Invasive Lumbar Decompression: Clinical Efficacy and Durability to 2 Years
}

Ryan Khanna, Hani Malone, Kavantissa M. Keppetipola, Harel Deutsch, Richard G. Fessler, Ricardo B. Fontes and John E. O'Toole

Int J Spine Surg 2021, 15 (4) 795-802

doi: https://doi.org/10.14444/8102

http://ijssurgery.com/content/15/4/795

This information is current as of April 26, 2023.

Email Alerts Receive free email-alerts when new articles cite this article. Sign up at: http://ijssurgery.com/alerts 


\title{
Multilevel Minimally Invasive Lumbar Decompression: Clinical Efficacy and Durability to 2 Years
}

\author{
RYAN KHANNA, MD, MBA, MSCI, ${ }^{1}$ HANI MALONE, MD,${ }^{2}$ KAVANTISSA M. KEPPETIPOLA, MD, ${ }^{1}$ \\ HAREL DEUTSCH, MD,${ }^{1}$ RICHARD G. FESSLER, MD, PhD,${ }^{1}$ RICARDO B. FONTES, MD, PhD ${ }^{1}$ \\ JOHN E. O'TOOLE, MD, MS ${ }^{1}$ \\ ${ }^{I}$ Department of Neurosurgery, Rush University Medical Center, Chicago, Illinois, ${ }^{2}$ Department of Neurosurgery, Scripps Clinic, La Jolla, California
}

\begin{abstract}
Background: The clinical efficacy of single-level minimally invasive lumbar decompression and/or microdiscectomy is well established, with improved postoperative functional outcome and pain scores. However, there is a paucity of clinical data supporting the use of minimally invasive (MIS) techniques in a single operation to address pathology at multiple lumbar levels, and this study attempts to address this issue.

Methods: A retrospective review of prospectively collected data from patients with symptomatic lumbar stenosis and/or disc herniations who underwent multilevel minimally invasive decompression or microdiscectomy from November 2014 to February 2018 was conducted at a single academic medical center. Patient-reported outcome measures (PROMs), including the Oswestry Disability Index (ODI), visual analog scale (VAS) for back and leg pain, 12Item Short Form Health Survey (SF-12) Physical Component Summary Score (PCS) and Mental Component Summary Score (MCS), and Scoliosis Research Society survey (SRS-30), were prospectively collected before surgery and at 3 months, 6 months, 1 year, and 2 years postoperatively.

Results: During the study period, 92 patients received multilevel ( $\geq 2$ level) MIS lumbar decompression and/or discectomy (69 two level, 21 three level, 2 four level). The mean age at surgery was 69.7 years, and $23(25 \%)$ patients were women. Patient-reported outcomes were significantly improved both in the short and long term except for the SF-12 MCS. Average improvement from baseline was (at 3 months and 2 years, respectively): VAS back, -3.9 and -2.8 ; VAS leg, -3.6 and -2.6; ODI, -13 and -14.6; SF-12 MCS, 2.8 and -0.3; SF-12 PCS, 6.9 and 10.1; and SRS-30, 0.57 and 0.55. Minimal clinically important difference for the study population was reached for every PROM except SF-12 MCS. Surgical complications occurred in 16 patients $(17.4 \%)$, and 8 patients $(8.6 \%)$ required postoperative fusions within 2 years.

Conclusion: The use of MIS techniques to perform lumbar decompression and/or discectomy at multiple levels was found to be both clinically effective and durable. Fusion rates remained low 2 years after the index surgery and were consistent with literature data for open procedures.
\end{abstract}

Level of Evidence: 2.

Minimally Invasive Surgery

Keywords: MIS, minimally invasive, decompression, discectomy, multilevel, laminectomy, PROM

\section{INTRODUCTION}

Lumbar spinal stenosis is a degenerative condition defined as narrowing of the central spinal canal, the vertebral foramina, and/or the lateral recesses, causing impingement on nearby neurologic structures. This condition largely affects the elderly and can cause a variety of debilitating symptoms, including back and radicular leg pain and neurogenic claudication. Similar symptoms can also occur due to vertebral disc herniation causing impingement on neurologic structures. In the absence of progressive neurologic deficit or intractable pain, first-line treatment is nonoperative, consisting of physical therapy and pharmacotherapy (analgesics, steroids). ${ }^{1}$
When nonoperative measures fail to provide relief, surgical decompression of the neural elements has been shown to significantly alleviate symptoms. ${ }^{2-7}$

Surgical techniques vary, but traditional "open" lumbar decompression procedures involve subperiosteal dissection of the paraspinal musculature to facilitate laminectomy and/or laminotomy. The adaptation of minimally invasive spine (MIS) techniques for single-level surgery allowed for equally efficacious lumbar decompressions with the goal of decreasing postoperative pain, muscle disruption, blood loss, and length of hospitalization. ${ }^{5,8,9}$ Several studies have reported that singlelevel MIS decompression of lumbar compressive 
pathology leads to improved postoperative functional outcome and pain scores. ${ }^{9,10}$ However, there is a paucity of clinical data to support the use of MIS decompression and/or discectomy to address pathology at multiple lumbar levels during a single operation. This study aims to investigate whether multilevel MIS decompression and/or discectomy leads to significant and durable improvements in postoperative function and pain scores.

\section{METHODS}

\section{Patient Population and Surgical Technique}

Following institutional review board approval, information for patients operated upon by 4 neurosurgeons at a large academic tertiary center were collected for a retrospective review of prospectively collected data from 2014-2018. All patients aged 45 years or older with symptomatic lumbar degenerative stenosis who underwent a posterior MIS decompression (laminectomy, foraminotomy, and/or discectomy) at 2 or more levels during the study period were included. Nondegenerative pathology (trauma, infection, neoplasms) or emergent procedures (precluding compilation of outpatient preoperative data) were not included.

\section{Decompressive Procedure}

Experienced neurosurgeons performed MIS decompressions, discectomies, and foraminotomies for patients with lumbar stenosis at $\geq 2$ levels. ${ }^{11,12}$ The technique of MIS laminectomy used was a modification of the technique of unilateral approach for bilateral decompression described by Guiot, Khoo, and Fessler ${ }^{12}$ in 2002, using $\times 3.5$ loupe magnification or the operative microscope. Under fluoroscopy, the desired level was identified and a paramedian skin incision made. Sequential dilators were used to place a tubular working channel $18-22 \mathrm{~mm}$ in diameter over the ipsilateral target lamina. Soft tissue was cleared, and a high-speed drill and/or Kerrison rongeur was used to perform an ipsilateral laminectomy while preserving the pars and cranial segment of the lamina. The cranial limit of the decompression was the insertion of the ligamentum flavum. For the contralateral part of the decompression, the flavum was maintained in place, the tube was aimed contralaterally, and a sublaminar or "over the top" laminectomy, medial facetectomy, and foraminotomy was performed. Resection of the ligamentum flavum and the contralateral medial facetectomy were completed using a Kerrison rongeur reaching from the tip of the superior articular process to the middle of the caudal pedicle. The contralateral disc and pedicle were visualized, and complete decompression of the contralateral traversing nerve root was confirmed. Sometimes, the ipsilateral medial facetectomy and foraminotomy was also finalized after the contralateral work was completed. In the case of a discectomy procedure, the contralateral work was not always necessary and after removal of the ligamentum flavum, the nerve root was retracted medially to expose the disc, in the usual fashion. ${ }^{13}$ This process was repeated at each level $(\geq 2)$ of the patient's pathology. The same incision could be used for immediately adjacent cranial and caudal levels, or alternating sides of the approach for different levels could be used to allow 2 surgeons to operate simultaneously if so desired. ${ }^{14}$ In all procedures used, the midline dorsal osseous and ligamentous structures were preserved.

\section{Data Collection and Analysis}

Demographic and surgical data were extracted from the electronic medical record. The incidence of additional lumbar surgical procedures including fusions after the index operation was determined, as were the reasons for these additional procedures and the presence of preoperative spondylolisthesis or scoliosis. Patient-reported outcome measures (PROMs) were digitally collected and tracked on a HIPAA-compliant online database (OBERD, Universal Research Solutions LLC, Columbia, MO). Preoperatively and at each follow-up clinic visit (scheduled at 3 months, 6 months, 1 year, and 2 years postoperatively), patients prospectively completed multiple questionnaires: Numeric Rating Scale for Back and Leg (NRS-B/L), Oswestry Disability Index (ODI), Mental and Physical component scores of the 12-item Short Form Health Survey (SF-12 MCS and PCS), and the Scoliosis Research Society survey (SRS-30). ${ }^{4-7}$

\section{Statistical Methods}

PROMs at each time were analyzed using the Student $t$ test and were compared with preoperative baseline, at a significance level of .05 .

\section{RESULTS}

\section{Patient Characteristics}

A total of 104 study-eligible patients underwent multilevel ( $\geq 2$ levels) MIS lumbar decompression, 
Table 1. Patient demographic and surgical data.

\begin{tabular}{lc}
\hline Parameter & Value \\
\hline Operated levels, n (\%) & \\
2 & $69(75)$ \\
3 & $21(22.8)$ \\
4 & $2(2.2)$ \\
Age, mean (range), y & $69.7(48-90)$ \\
Sex, n (\%), M:F & $69: 23(75: 25)$ \\
OR time, mean (range), min & $117(20-270)$ \\
Blood loss, mean (range), mL & $79(20-300)$ \\
Complications, n (\%) & \\
Durotomy & $15(16.3)$ \\
Epidural hematoma & $1(1.1)$ \\
Delayed pseudomeningocele & $1(1.1)$ \\
\hline
\end{tabular}

Abbreviation: OR, operating room.

discectomy, and/or foraminotomy from 2014-2018 (Table 1). Twelve patients were excluded due to a lack of adequate PROMs preoperatively or postoperatively. A total of 69 patients had 2-level procedures, 21 had 3-level procedures, and two had 4-level procedures. Mean age at surgery was $69.7 \pm 9$ years, and $25 \%$ of the patients were women. The mean operative time was $117 \pm 63$ minutes and mean estimated blood loss was $79 \mathrm{~mL}$. Two-level surgeries lasted on average 106 minutes, 3-level surgeries lasted on average 143.5 minutes, and 4-level surgeries lasted on average 195 minutes. For 2-level surgeries, 14 out of $69(20.3 \%)$ resulted in complications; for 3-level surgeries, 2 out of $21(9.5 \%)$ resulted in complications; and for 4-level surgeries, there were no complications in 2 patients. Fifteen cases $(16 \%)$ were complicated by a durotomy. Most of these (11 cases) were treated by buttressing the durotomy with gelatin sponge and dural sealant. Four patients underwent primary suture repair during the initial surgery. When broken down per level, the durotomy rate was $7.2 \%$. No reoperations were necessary for pseudomeningocele, although 1 case was managed with a blood patch and lumbar drainage at 2 months postoperatively. The single early reoperation $(1.1 \%)$ in our series was due to an epidural hematoma that required a return to the operating room on postoperative day 3 . At the 3month follow-up, $95 \%$ of patients had completed their online PROM forms. This number decreased to $68 \%, 50 \%$, and $24 \%$ at 6,12 , and 24 months, respectively. We had clinical follow-up through electronic medical record for additional operations (no PROMs) for $100 \%$ of patients at 3 months, $95 \%$ at 6 months, $86 \%$ at 1 year, and $61 \%$ at 2 years.

\section{Patient-Reported Outcome Measures}

The average of each preoperative PROM is reported in Table 2, as is the average postoperative change from baseline at each time point. To establish the clinical significance of these values, the minimum clinically importance difference (MCID) was also reported. ${ }^{15,16}$ All postoperative values were statistically significantly improved compared with preoperative values $(P<.001)$ except the 3 -month SF-12 MCS $(P=.016), 6$-month SF-12 MCS $(P=.904), 1$ year SF-12 MCS $(P=.326)$, and 2-year SF-12 MCS $(P=.882$; Table 2 and Figure 1$)$. In addition, Table 3 details the percentage of patients who reached MCID at each postoperative time point.

\section{Postoperative Fusions}

At the 2-year follow-up, 8 of our 92 patients (8.7\%) went on to require a lumbar fusion at an average of 485 days postoperatively. Table 4 lists the initial surgery, the follow-up fusion, the postoperative day from the index operation, preoperatively spondylolisthesis or scoliosis, and the reason for the follow-up fusion. In Figure 2, we detail the preoperative, postoperative but prefusion, and postfusion imaging of patient 7 (64-year-old man) as an example of a patient who ultimately required lumbar fusion. In this case, adequate decompression was achieved following L3L5 laminectomy; however, the patient developed a grade I spondylolisthesis and ultimately required L4L5 transforaminal lumbar interbody fusion.

\section{DISCUSSION}

Symptomatic lumbar stenosis is one of the few neurosurgical pathologies for which there is level 1

Table 2. Baseline PROM and postoperative change, mean \pm standard deviation.

\begin{tabular}{lccccc}
\hline & Preoperative & $\mathbf{3 ~ m o}$ & $\mathbf{6 ~ m o}$ & $\mathbf{1} \mathbf{y}$ & $\mathbf{2} \mathbf{y}$ \\
\hline NRS-B & $6.4 \pm 2.4$ & $-3.9 \pm 3.0^{\mathrm{a}}$ & $-3.5 \pm 2.9^{\mathrm{a}}$ & $-2.5 \pm 3.2^{\mathrm{a}}$ & $-2.8 \pm 2.4^{\mathrm{a}}$ \\
NRS-L & $6.4 \pm 2.3$ & $-3.6 \pm 3.1^{\mathrm{a}}$ & $-3.5 \pm 3.4^{\mathrm{a}}$ & $-3.2 \pm 3.5^{\mathrm{a}}$ & $-2.6 \pm 2.9^{\mathrm{a}}$ \\
ODI & $36.2 \pm 14.2$ & $-13.0 \pm 19.2^{\mathrm{a}}$ & $-13.5 \pm 17.7^{\mathrm{a}}$ & $-13.6 \pm 18.9^{\mathrm{a}}$ & $-14.6 \pm 13.9^{\mathrm{a}}$ \\
SF-12 MCS & $52.5 \pm 10.8$ & $2.8 \pm 10.0$ & $-0.2 \pm 10.6$ & $1.6 \pm 9.9$ & $-0.3 \pm 10.4$ \\
SF-12 PCS & $28.8 \pm 7.3$ & $6.9 \pm 10.7^{\mathrm{a}}$ & $10.7 \pm 10.8^{\mathrm{a}}$ & $10.5 \pm 12.0^{\mathrm{a}}$ & $10.1 \pm 10.5^{\mathrm{a}}$ \\
SRS-30 & $3.20 \pm 0.54$ & $0.57 \pm 0.57^{\mathrm{a}}$ & $0.62 \pm 0.65^{\mathrm{a}}$ & $0.62 \pm 0.69^{\mathrm{a}}$ & $0.55 \pm 0.57^{\mathrm{a}}$ \\
\hline
\end{tabular}

Abbreviations: MCS, Mental Component Score; NRS-B, Numeric Rating Scale-Back; NRS-L, Numeric Rating Scale-Leg; ODI, Oswestry Disability Index; PCS, Physical Component Score; SF-12, 12-item Short Form Health Survey; SRS-30, Scoliosis Research Society survey.

${ }^{\mathrm{a}} p<.001$ compared with preoperative value. 
a.

NRS-B: Change in Back Pain by Post-Operative Years from Decompression

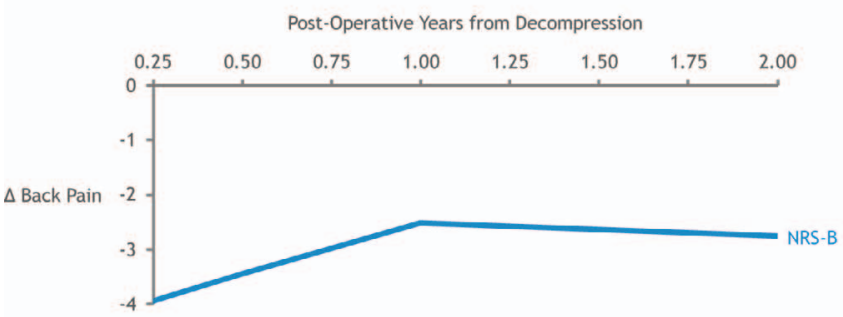

b.

NRS-L: Change in Leg Pain by Post-Operative Years from Decompression

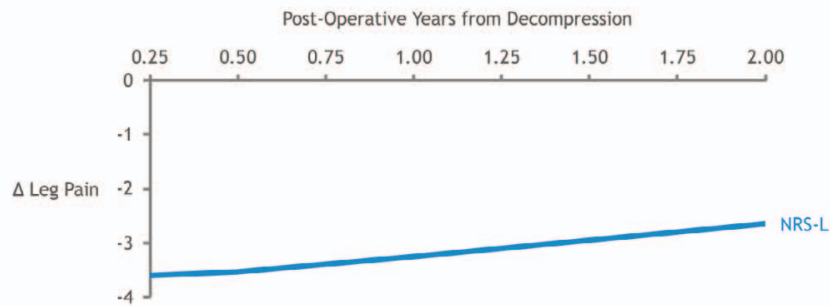

c.

ODI: Change by Post-Operative Years from Decompression

Post-Operative Years from Decompression

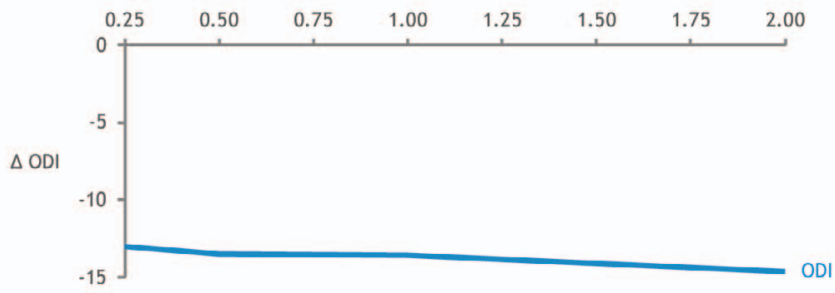

d. SF12-M: Change by Post-Operative Years from Decompression

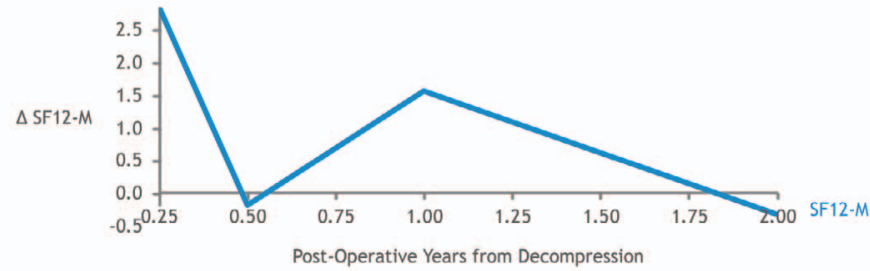

e. SF12-P: Change by Post-Operative Years from Decompression

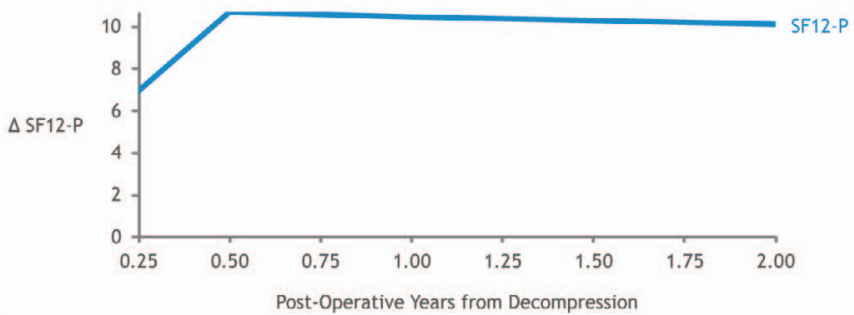

f.

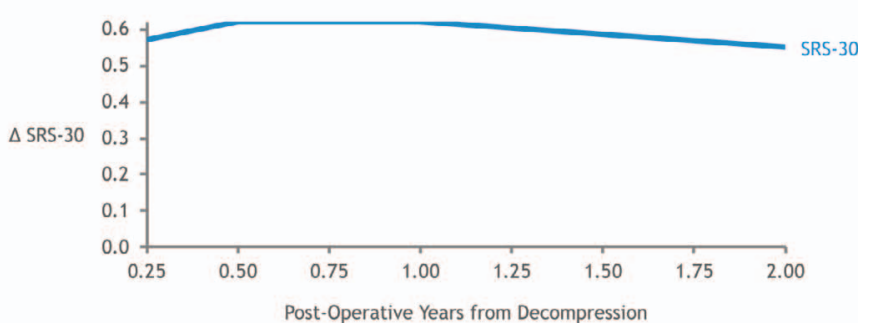

Figure 1. Comparison of change of PROM from preoperative baseline at 3 months, 6 months, 1 year, and 2 years postoperatively from index decompression: (a) NRSB, (b) NRS-L, (c) ODI, (d) SF12-M, (e) SF12-P, (f) SRS-30). Abbreviations: M, Mental Component Score; NRS-B, Numeric Rating Scale-Back; NRS-L, Numeric Rating Scale-Leg; ODI, Oswestry Disability Index; P, Physical Component Score; SF-12, 12-item Short Form Health Survey; SRS-30, Scoliosis Research Society survey.

evidence of surgical treatment being superior to prolonged nonoperative management for up to 8 years after the index operation. ${ }^{6,17}$ The Spine Patient Outcomes Research Trial (SPORT) included patients with both single-level and multilevel symptomatic compression, but patient outcomes were not analyzed in terms of number of operated levels. There have been a few publications suggesting that

Table 3. Percentage of patients who met MCID at each time point.

\begin{tabular}{lccccr}
\hline & $\mathbf{3} \mathbf{~ m o}$ & $\mathbf{6} \mathbf{~ m o}$ & $\mathbf{1} \mathbf{y}$ & $\mathbf{2 ~ y}$ & $\mathbf{M C I D}^{\mathbf{a}}$ \\
\hline NRS-B & 80.3 & 77.6 & 65.8 & 68.2 & -1.2 \\
NRS-L & 72.6 & 80.0 & 73.7 & 63.6 & -1.6 \\
ODI & 56.2 & 52.9 & 47.4 & 52.4 & -12.8 \\
SF12-M & 42.7 & 32.1 & 35.0 & 40.9 & 3.7 \\
SF12-P & 63.5 & 59.6 & 69.2 & 81.0 & 3.3 \\
SRS-30 & 63.5 & 59.6 & 59.0 & 57.1 & 0.4
\end{tabular}

Abbreviations: M, Mental Component Score; MCID, minimally clinically important difference; NRS-B, Numeric Rating Scale-Back; NRS-L, Numeric Rating Scale-Leg; ODI, Oswestry Disability Index; P, Physical Component Score; SF-12, 12-item Short Form Health Survey; SRS-30, Scoliosis Research Society survey.

${ }^{\mathrm{a}} \mathrm{MCID}$ is the reference point to compare to all other columns. patients undergoing multilevel decompressions for stenosis have worse outcomes than those undergoing single-level surgery. Ulrich et $\mathrm{al}^{18}$ have recently reported similar long-term PROM outcomes but significantly higher rates of perioperative complications in patients undergoing multilevel decompressions. Adilay and Guclu ${ }^{19}$ reported worse outcome scores for patients undergoing multilevel decompressions, in addition to higher perioperative complications. These findings are likely a reflection of the increased magnitude of the surgery and possibly greater age or comorbidities in those patients who require multilevel decompression. In that regard, the use of MIS techniques are appealing when developing surgical treatment plans for such patient populations. We have attempted to demonstrate that improvement afforded by multilevel decompression when using MIS techniques is durable and, and similarly durable to open techniques without increased need for reoperations. 
Table 4. Secondary surgery data.

\begin{tabular}{|c|c|c|c|c|c|}
\hline Patient & Index Surgery & Fusion & PO day No. & Preoperative Deformity & Indication for Revision \\
\hline 1 & L2-L4 laminectomy & L3-L4 LLIF & 229 & No & Worsening foraminal stenosis at L3-L4 \\
\hline 2 & $\begin{array}{l}\text { L2-L3 laminectomy, L3-L4 } \\
\text { foraminotomy }\end{array}$ & L2-L5 LLIF & 553 & $\begin{array}{l}8^{\circ} \mathrm{L} 2-\mathrm{L} 3 \text { focal coronal } \\
\text { curve }\end{array}$ & Progression scoliosis to $14^{\circ}$, foraminal stenosis \\
\hline 3 & L2-L3 MED, L4-5 laminectomy & L4-L5 TLIF & 693 & $\begin{array}{l}\text { GII L4-L5 listhesis, } \\
18^{\circ} \text { scoliosis }\end{array}$ & Stable listhesis, scoliosis progressed to $29^{\circ}$ \\
\hline 4 & L4-S1 laminectomy & L3-pelvis PSF & 243 & GI L5-S1 listhesis & Stable listhesis, worsening foraminal stenosis \\
\hline 5 & L4-L5, L5-S1 MEDs & L5-S1 TLIF & 625 & GI L5-S1 listhesis & Progression listhesis to GII \\
\hline 6 & L3-L4, L5-S1 laminectomies & L4-5 TLIF & 728 & No & Development GI L4-L5 listhesis \\
\hline 7 & L3-L5 laminectomy & L4-L5 TLIF & 511 & No & Development GI L4-5 listhesis \\
\hline 8 & L3-S1 laminectomy & L3-L5 LLIF & 294 & No & Persistent foraminal stenosis \\
\hline
\end{tabular}

Abbreviations: GI, grade I; GII, grade II; LLIF, lateral lumbar interbody fusion; MED, microdiscectomy; PO, postoperative; PSF, posterior spinal fusion; TLIF, transforaminal interbody fusion.

There is significant evidence that MIS techniques applied to single-level lumbar pathology result in decreased estimated blood loss, tissue injury, and fewer perioperative complications. ${ }^{20,21}$ The questions surrounding MIS applicability to multilevel stenosis involve, first, its ability to effectively decompress the canal (ie, short-term improvement) but also whether that improvement is durable without development of structural complications sooner than with open procedures (ie, spondylolisthesis, scoliosis, or restenosis). In this study, we were able to prospectively collect 2-year PROM for patients undergoing min- imally invasive decompressions for lumbar stenosis at multiple levels. Short-term results of the effectiveness of MIS decompression for stenosis were redemonstrated, but our study population also demonstrated sustained and statistically significant improvement beyond MCID in all PROM categories except for the SF-12 MCS at the 3-month, 6-month, 1 -year, and 2-year time points. Complications were relatively few including a $16.3 \%$ durotomy rate per patient and 1 patient requiring evacuation of a postoperative hematoma. This complication pattern is consistent with prior studies for both 1-level

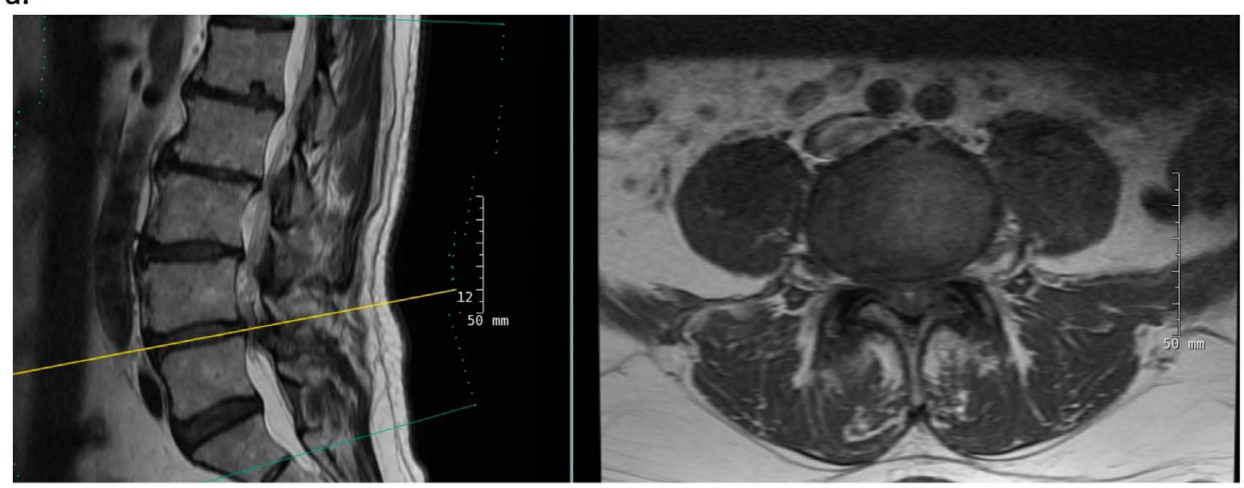

b.

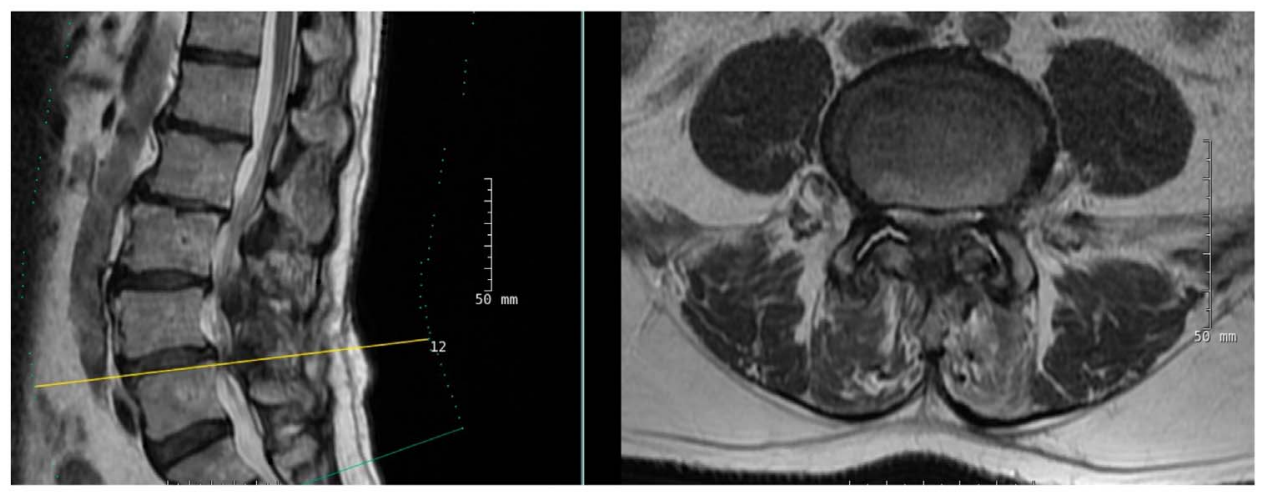

c.

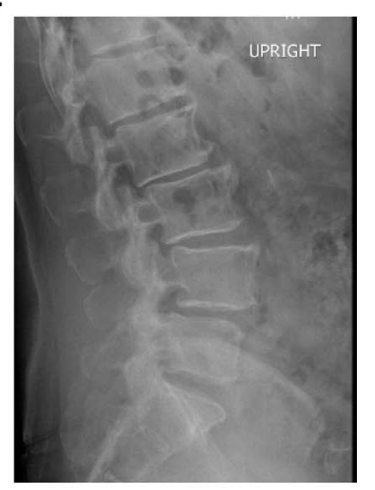

d.

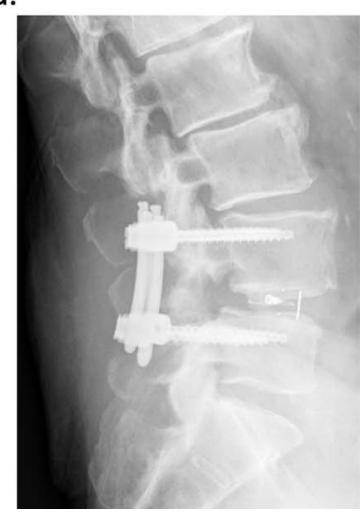

Figure 2. Example of patient who ultimately required lumbar fusion after original decompression. (a) Preoperative sagittal and axial MRI at L4-5 prior to L3-5 MIS laminectomy. (b) Postoperative sagittal and axial MRI at L4-L5 after L3-L5 MIS laminectomy. (c) Upright XR demonstrating postoperative grade I spondylolisthesis at L4-L5. (d) Postoperative upright XR after L4-L5 TLIF. TLIF, transforaminal lumbar interbody fusion; XR, x-ray. 
pathology and open surgical approaches. ${ }^{19,22-24}$ As shown by the SPORT data, multilevel cases have higher durotomy rates due to the larger extent of exposed dura. ${ }^{25}$ Similarly to most minimally invasive studies, there were no surgical site infections. ${ }^{26,27}$ Durotomies were mostly managed with a bloodsoaked gelatin sponge buttress and dural sealant, rarely requiring direct suturing (only 4 patients), and overnight bedrest. No reoperations were necessary for durotomy, although 1 patient required a blood patch with lumbar drain for repair of pseudomeningocele 2 months postoperatively.

Beyond short-term efficacy and safety, long-term durability is a concern regarding multilevel MIS decompression. Historically, the development of postoperative spondylolisthesis is the classical postoperative sign of structural progression and has even been termed iatrogenic. However, the spondylolisthesis itself may not completely capture all the indications for a patient requiring a fusion following a laminectomy, and only rarely can a pars fracture be identified in those patients who develop the spondylolisthesis. Other signs of progressive structural compromise include worsening of a coronal deformity leading to foraminal stenosis, back pain consequent to disc degeneration, or persistence or worsening of foraminal stenosis requiring a full facetectomy for foraminal decompression, for example. Several anatomical and surgical factors are thought to influence the development of structural progression: Soft tissue disruption, extent of facetectomy, number of levels operated on, sagittal balance, and disc height are the most frequently quoted. ${ }^{28}$ In addition, lumbar decompression is frequently offered as a "first-tier" operation to patients with varying degrees of preexisting foraminal stenosis, spondylolisthesis, and scoliosis in lieu of a more invasive, rigid fusion. In the SPORT trial for stenosis, reoperation rates at 2 years for the observational and randomized cohorts were $8 \%$ and $6 \%$, respectively. ${ }^{6}$ At 8 years, these numbers had increased to $17 \%$ and $19 \%$, respectively. ${ }^{17}$ The reported rate of reoperation after laminectomy in the literature from 1976-2015 varies from $1.6 \%-32 \%$, significantly affected by multiple factors such as historical period, geographical location, and attitude regarding recurrent low back symptoms following a decompression. In another modern series, Ramhmdani et $\mathrm{al}^{28}$ reported a $9.5 \%$ rate of fusion following a 1- to 4-level open laminectomy, at an average of 19 months following the index operation.
Minimally invasive techniques, particularly when using unilateral access for bilateral decompression (aka "over-the-top" decompression), offer an appealing alternative by minimizing some of the proposed mechanisms of structural progression such as ligament and muscle damage and extent of facetectomy. In our series, $9 \%$ of our patients required subsequent fusion at an average of 16 months after decompression, which is consistent with published data. It should be noted that $50 \%$ of these patients had preexisting spondylolisthesis or scoliosis, an element that is absent from most multilevel laminectomy series. In these cases, each of the patients were counseled that a fusion may be necessary, but in conjunction with the surgeon, patients made the decision to undergo a smaller procedure first to see if it alleviated their symptoms.

To our knowledge, this is the first study that demonstrates durable clinical effectiveness of multilevel MIS lumbar decompression out to 2 years postoperatively, consistent with 1-level data and comparing favorably with open multilevel series. ${ }^{29}$ There are several limitations to this study. Despite effort to prospectively collect all clinical data, lost to follow-up rates were $14.1 \%(13 / 92)$ of patients at 1 year and $39.1 \%(36 / 92)$ at 2 years. The results described here obviously might be different from results if these patients sought care elsewhere for poor results of initial decompression, but they could also be interpreted as the patients being symptomfree and following up locally. In our experience the 1 -year clinical follow-up rate of $85.9 \%$ is quite high for a decompression-only study in a location without a clinically dominant hospital system and long travel times to a tertiary academic institution. External validity of these results may also be an issue because this study was performed at an academic institution where all participating surgeons were proficient with MIS techniques and had more than 5 years of experience. Over $90 \%$ of lumbar decompressions at our institution are, in fact, performed MIS, and given the learning curve, these results may not be immediately generalizable. ${ }^{30}$ Finally, longer-term follow-up is necessary as shown in the SPORT trial, in which the reoperation rates continued to steadily rise up to 8 years after surgery.

\section{CONCLUSION}

This study provides evidence that the use of MIS surgical techniques to treat multilevel lumbar 
stenosis is clinically effective and durable up to 2 years postoperatively with low rates of complications and reoperations. These data may support the creation of a randomized prospective trial to provide a more robust evidence base comparing MIS with open techniques in multilevel decompressive procedures in the lumbar spine. MIS is quickly progressing to becoming not simply an established surgical method for lumbar stenosis but perhaps the preferred surgical technique pending additional investigation.

\section{REFERENCES}

1. Lurie J, Tomkins-Lane C. Management of lumbar spinal stenosis. BMJ. 2016;352:h6234.

2. Ahmad S, Hamad A, Bhalla A, et al. The outcome of decompression alone for lumbar spinal stenosis with degenerative spondylolisthesis. Eur Spine J. 2017;26:414-419.

3. Katz JN, Lipson SJ, Lew RA, et al. Lumbar laminectomy alone or with instrumented or noninstrumented arthrodesis in degenerative lumbar spinal stenosis. Patient selection, costs, and surgical outcomes. Spine (Phila Pa 1976). 1997;22:11231131.

4. Forsth P, Michaelsson K, Sanden B. Does fusion improve the outcome after decompressive surgery for lumbar spinal stenosis? A two-year follow-up study involving 5390 patients. Bone Joint J. 2013;95-b:960-965.

5. Thome C, Zevgaridis D, Leheta O, et al. Outcome after less-invasive decompression of lumbar spinal stenosis: a randomized comparison of unilateral laminotomy, bilateral laminotomy, and laminectomy. J Neurosurg Spine. 2005;3:129141.

6. Weinstein JN, Tosteson TD, Lurie JD, et al. Surgical versus nonsurgical therapy for lumbar spinal stenosis. $N$ Engl J Med. 2008;358:794-810.

7. Kovacs FM, Urrutia G, Alarcon JD. Surgery versus conservative treatment for symptomatic lumbar spinal stenosis: a systematic review of randomized controlled trials. Spine (Phila Pa 1976). 2011;36:E1335-E1351.

8. Nerland US, Jakola AS, Solheim O, et al. Minimally invasive decompression versus open laminectomy for central stenosis of the lumbar spine: pragmatic comparative effectiveness study. BMJ. 2015;350:h1603.

9. Phan K, Mobbs RJ. Minimally invasive versus open laminectomy for lumbar stenosis: a systematic review and metaanalysis. Spine (Phila Pa 1976). 2016;41:E91-E100.

10. Nerland US, Jakola AS, Solheim O, et al. Minimally invasive decompression versus open laminectomy for central stenosis of the lumbar spine: pragmatic comparative effectiveness study. BMJ. 2015;350:h1603.

11. Bresnahan L, Ogden AT, Natarajan RN, et al. A biomechanical evaluation of graded posterior element removal for treatment of lumbar stenosis: comparison of a minimally invasive approach with two standard laminectomy techniques. Spine (Phila Pa 1976). 2009;34:17-23.

12. Guiot BH, Khoo LT, Fessler RG. A minimally invasive technique for decompression of the lumbar spine. Spine (Phila Pa 1976). 2002;27:432-438.

13. McGrath LB, White-Dzuro GA, Hofstetter CP. Com- parison of clinical outcomes following minimally invasive or lumbar endoscopic unilateral laminotomy for bilateral decompression. J Neurosurg Spine. 2019:1-9.

14. Khoo LT, Fessler RG. Microendoscopic decompressive laminotomy for the treatment of lumbar stenosis. Neurosurgery. 2002;51:S146-S154.

15. Knio ZO, Schallmo MS, Hsu W, et al. Unilateral laminotomy with bilateral decompression: a case series studying one- and two-year outcomes with predictors of minimal clinical improvement. World Neurosurg. 2019; e290-297.

16. Díaz-Arribas MJ, Fernández-Serrano M, Royuela A, et al. Minimal clinically important difference in quality of life for patients with low back pain. Spine (Phila Pa 1976). 2017;42:1908-1916.

17. Lurie JD, Tosteson TD, Tosteson A, et al. Long-term outcomes of lumbar spinal stenosis: eight-year results of the Spine Patient Outcomes Research Trial (SPORT). Spine (Phila Pa 1976). 2015;40:63-76.

18. Ulrich NH, Burgstaller JM, Held U, et al. The influence of single-level versus multilevel decompression on the outcome in multisegmental lumbar spinal stenosis: analysis of the Lumbar Spinal Outcome Study (LSOS) data. Clin Spine Surg. 2017;30:E1367-E1375.

19. Adilay U, Guclu B. Comparison of single-level and multilevel decompressive laminectomy for multilevel lumbar spinal stenosis. World Neurosurg. 2018;111:e235-e240.

20. Bresnahan LE, Smith JS, Ogden AT, et al. Assessment of paraspinal muscle cross-sectional area after lumbar decompression: minimally invasive versus open approaches. Clin Spine Surg. 2017;30:E162-E168.

21. Ahn J, Iqbal A, Manning BT, et al. Minimally invasive lumbar decompression - the surgical learning curve. Spine J. 2016;16:909-916.

22. Epstein NE. Lower complication and reoperation rates for laminectomy rather than MI TLIF/other fusions for degenerative lumbar disease/spondylolisthesis: a review. Surg Neurol Int. 2018;9:55.

23. Bydon M, Macki M, Abt NB, et al. Clinical and surgical outcomes after lumbar laminectomy: an analysis of 500 patients. Surg Neurol Int. 2015;6:S190-S193.

24. Herren C, Sobottke R, Mannion AF, et al. Incidental durotomy in decompression for lumbar spinal stenosis: incidence, risk factors and effect on outcomes in the Spine Tango registry. Eur Spine J. 2017;26:2483-2495.

25. Desai A, Ball PA, Bekelis K, et al. SPORT: Does incidental durotomy affect long-term outcomes in cases of spinal stenosis? Neurosurgery. 2015;76(suppl 1):S57-S63, discussion S63.

26. Kulkarni AG, Patel RS, Dutta S. Does minimally invasive spine surgery minimize surgical site infections? Asian Spine J. 2016;10:1000-1006.

27. Ee WW, Lau WL, Yeo W, et al. Does minimally invasive surgery have a lower risk of surgical site infections compared with open spinal surgery? Clin Orthop Relat Res. 2014;472:1718-1724.

28. Ramhmdani S, Xia Y, Xu R, et al. Iatrogenic spondylolisthesis following open lumbar laminectomy: case series and review of the literature. World Neurosurg. 2018;113:e383-e90.

29. Epstein NE. More nerve root injuries occur with minimally invasive lumbar surgery: let's tell someone. Surg Neurol Int. 2016;7:S96-S101. 
30. Epstein NE. Learning curves for minimally invasive spine surgeries: are they worth it? Surg Neurol Int. 2017;8:61.

Disclosures and COI: No financial support was required for this study. The authors report no conflicts of interest.

Corresponding Author: Ryan Khanna, MD, MBA, MSCI, Department of Neurosurgery, Rush University Medical Center, 1725 West Harrison St,
Suite 855, Chicago, IL 60612. Phone: (312) 942-6644; Fax:(312)942-2176; Email: ryan_khanna@rush.edu.

Published 19 August 2021

This manuscript is generously published free of charge by ISASS, the International Society for the Advancement of Spine Surgery. Copyright $\odot 2021$ ISASS. To see more or order reprints or permissions, see http://ijssurgery.com. 